\title{
Performance Evaluation of Crumb Rubber Modified Stone Mastic Asphalt Pavement in Malaysia
}

\author{
Nuha Salim Mashaan, Asim H. Ali, Suhana Koting, and Mohamed Rehan Karim \\ Center for Transportation Research, Faculty of Engineering, University of Malaya, 50603 Kuala Lumpur, Malaysia \\ Correspondence should be addressed to Nuha Salim Mashaan; nuhaasim@yahoo.com
}

Received 26 May 2013; Accepted 11 July 2013

Academic Editor: Wen-Hua Sun

Copyright ( 2013 Nuha Salim Mashaan et al. This is an open access article distributed under the Creative Commons Attribution License, which permits unrestricted use, distribution, and reproduction in any medium, provided the original work is properly cited.

\begin{abstract}
To prevent pavement distresses there are various solutions such as adopting new mix designs or utilisation of asphalt additives. The primary aim of this study was to investigate the effect of adding crumb tyre rubber as an additive to SMA mixture performance properties. This study investigated the essential aspects of modified asphalt mixtures in order to better understand the influence of CRM modifiers on volumetric, mechanical, and stiffness properties of SMA mixture. In this study, virgin bitumen $80 / 100$ penetration grade was used, modified with crumb rubber (CRM) at five different modification levels, namely, 6\%, 12\%, 16\%, and $20 \%$, respectively, by weight of the bitumen. The appropriate amount of the added CRM was found to be $12 \%$ by weight of bitumen. This percentage results in the maximum level of stability. The resilient modulus (Mr) of modified SMA samples including different percentages of CRM was obviously higher in comparison with that of unmodified samples.
\end{abstract}

\section{Introduction}

Bitumen is considered as a thermoplastic viscoelastic adhesive and it has been used for road and highway pavement, primarily because of its good cementing power and waterproof properties [1]. The complexity in the chemistry of bitumen products is due primarily to the intricate composite of petroleum crude oils from which bitumen products are derived. Due to the inherent weaknesses of conventional bitumen which have led to high maintenance cost of the highway systems, there has been the need to modify bitumen. Modification/reinforcement of bitumen binder is possible during different stages of its usage, either in between binder production and mix processes or before paving mix production [2].

Stone mastic asphalt (SMA) is a hot asphalt paving mixture, developed in Germany during the mid-1960's [3] to provide maximum resistance to rutting caused by the studded tyres on European roads. In recognition of its excellent performance a national standard was set in Germany in 1984. Since the SMA has spread throughout Europe, North America, and Asia Pacific, several individual Countries in Europe now have a national standard for stone mastic asphalt, and CEN, the European standards body, is in the process of developing a European product standard. Today, SMA is widely employed in many countries in the world as an overlay or surface course to resist load induced and its popularity is increasing amongst road authorities and the asphalt industry.

The increased demand on highway roads might reduce its strength properties and make roads more susceptible to permanent distresses and failure. In general, pavement performance properties are affected by the bitumen binder properties; it is known that the conventional bitumen has a limited range of rheological properties and durability that are not sufficient enough to resist pavement distresses. Therefore, bitumen researchers and engineers are looking for different types of bitumen modifiers with excellent rheological properties, which directly affect asphalt pavement performance. Worldwide, there are many additives used as reinforcing material into the bituminous mixes, such as styrene butadiene styrene (SBS), synthetic rubber-styrenebutadiene (SBR), natural rubber, fibre, and crumb rubber modifier (CRM). The use of commercial polymers such as SBS and SBR in road and pavement construction will increase the construction cost as they are highly expensive materials. However, with the use of alternative materials such as crumb 
rubber modifier (CRM), it will definitely be environmentally beneficial, and not only it can improve the bitumen binder properties and durability, but it also has a potential to be cost effective [4].

Crumb rubber or waste tyre rubber is a blend of synthetic rubber, natural rubber, carbon black, antioxidants, fillers, and extender type of oils which are soluble in hot paving grade. Rubberised asphalt is obtained by the incorporation of crumb rubber from ground tyres in asphalt binder at certain conditions of time and temperature using either dry process method that adds granulated or crumb rubber modifier (CRM) from scrap tires as a substitute for a percentage of the aggregate in the asphalt concrete mixture, not as part of the asphalt binder, or wet processes (method of modifying the asphalt binder with CRM from scrap tires before the binder is added to form the asphalt concrete mixture). There are two rather different methods in the use of tyre rubber in bitumen binders first, by dissolving crumb rubber in the bitumen as binder modifier second, by substituting a portion of fine aggregates with ground rubber that does not completely react with bitumen [5]. In 1840s, the earliest experiments had involved incorporating natural rubber into asphalt binder to increase its engineering performance properties. The process of asphalt modification involving natural and synthetic rubber was introduced as early as 1843 [6]. In 1923, natural and synthetic rubber modifications in bitumen were further improved [7, 8]. According to Yildrim [8] the development of rubber-bitumen materials being used as joint sealers, patches, and membranes began in the late 1930s. The first attempt to modify bituminous binders by adding rubber was made in 1898 by Gauedmberg, who patented a process for manufacturing rubber bitumen. France was then given credit for installing the first road with a rubberised bituminous surfacing material [9]. The application of rubber-modified asphalt pavement started in Alaska in 1979. Placement of seven rubberised pavements totalling 4 lane-km using the Plus Ride dry process between 1979 and 1981 was reported. The performance of these sections in relation to mixing, compaction, durability, fatigue, stability and flow, and tyre traction and skid resistance was described. Rubberised bitumen using the wet process was first applied in Alaska in 1988 [10]. Lundy et al. (1993) [11] presented three case studies using crumb rubber with both the wet process and dry process at Mt. St. Helens Project, Oregon Dot, and Portland Oregon. The results showed that, even after a decade of service, crumb rubber products have excellent resistance to thermal cracking. Although rubber asphalt mixtures can be built successfully, quality control ought to be maintained for good performance.

Rubber pavement association found that using tyre rubber in open-graded mixture binder could decrease tyre noise by approximately $50 \%$. Also, in spray applications, rubber particles of multiple sizes had better sound absorption [12]. Moreover, another advantage of using asphalt rubber is to increase the lifespan of the pavement. However, recommendations were made to assess the cost effectiveness of asphalt rubber [5].

In Malaysia, the use of crumb rubber as an additive for road pavement construction supposedly started in the 1940s, but there has not been any official record of such practices. The first recorded trial using rubberised bitumen technology was reported in 1988, and the wet mix process was used with the mix of rubber additives in the form of latex into bitumen binder [13]. In 1993, another rubberised road trial using waste gloves and natural rubber latex was carried out in Negeri Sembilan [14]. In addition, Malaysia's production of scrap tyres is about 10 million pieces per annum, and unfortunately they are being disposed in an environmentally unfriendly manner. To minimise the damage of pavement such as resistance to rutting and fatigue cracking, asphalt needs to be modified with selected polymer such as crumb rubber modifier (CRM), and it will definitely be environmentally beneficial as well as improve the bitumen properties, durability, and reduces cost of rehabilitation [15-19].

Problem statement and aim of study: virgin bitumen 80/100 penetration grade is commonly used in Malaysia, and, moreover, it is subjected to high traffic loading and hot weather conditions. The weather condition in Malaysia leads to variation of temperature of about $55^{\circ} \mathrm{C}$ at the surface to $25^{\circ} \mathrm{C}$ at the subgrade during hot days. Due to an increase in service traffic density, axle loading, and low maintenance services, road structures have deteriorated and are therefore subjected to failure more rapidly. The main aim of this study was to investigate the effect of adding crumb tyre rubber as an additive to SMA mixture performance properties. This study investigated the essential aspects of modified asphalt mixtures in order to better understand the influence of CRM modifiers on the volumetric, mechanical as well as stiffness properties resistance of SMA mixture.

\section{Materials and Methods}

The experimental program in this study aims to investigate the effect of CRM on the rheological characterises of rubberised bitumen and mechanical properties of rubberised SMA mixtures.

2.1. Materials. Bitumen with $80 / 100$ penetration grade and average softening point of $47^{\circ} \mathrm{C}$ was utilized. Tables 1 and 2 illustrate some the physical properties and chemical constitutions of the bitumen, respectively. In this study, the gradation of crumb rubber no. $40(0.45 \mathrm{~mm})$ was selected. The density of crumb rubber is about $1.15\left(\mathrm{gm} / \mathrm{cm}^{3}\right)$. The crumb rubber modifier (CRM) produced by mechanical shredding at ambient temperature was obtained from Rubberplas Sdn. Bhd. (Malaysian supplier). CRM chemical components are illustrated in Table 3.

Crushed granite with SMA 14 aggregates was supplied from Kajang quarry (near Kuala Lumpur, Capital of Malaysia) was used throughout the study. The aggregate gradation of the adopted aggregate is according to JKR Malaysia standard [20] as illustrated in Table 4.

2.2. Sample Preparations and Test Method. Marshall design method was used for the modified and unmodified asphalt concrete mixtures. To incorporate rubber in bituminous mix, 
TABLE 1: Physical properties of bitumen.

\begin{tabular}{lcc}
\hline Bitumen test & $\begin{array}{c}\text { Bitumen grade } \\
80 / 100\end{array}$ & Standard test methods \\
\hline Viscosity @ 135 $\mathrm{C}(\mathrm{mPas})$ & 306.7 & ASTM D4402 \\
Ductility @ 25 $\mathrm{C}$ & $>100$ & ASTM D113 \\
Softening point @ 25 $\mathrm{C}$ & 47 & ASTM D36 \\
Penetration @ 25 $\mathrm{C}$ & 88 & ASTM D5 \\
Specific gravity @ 25 $5^{\circ} \mathrm{C}$ & 1.02 & ASTM D70 \\
Flash point @ ${ }^{\circ} \mathrm{C}$ & 305 & ASTM D92 \\
\hline
\end{tabular}

TABLE 2: Chemical composition of bitumen (\%).

\begin{tabular}{lc}
\hline Bitumen & $80 / 100$ \\
\hline Saturated & 5.4 \\
Aromatic & 72.5 \\
Resin & 15.5 \\
Asphaltene & 6.6 \\
\hline
\end{tabular}

TABLE 3: Chemical components of CRM no. 40 [9].

\begin{tabular}{lc}
\hline Chemical components & Test result \\
\hline Acetone extract (\%) & 23.1 \\
Rubber hydrocarbon (\%) & 46.6 \\
Carbon black content (\%) & 25.08 \\
Natural rubber content (\%) & 43.85 \\
Ash content (\%) & 5.2 \\
Particle size $(\mu)$ & 425 \\
\hline
\end{tabular}

TABLE 4: SMA 14 aggregate gradation [20].

\begin{tabular}{lccccc}
\hline \multirow{2}{*}{ B.S sieve } & \multicolumn{3}{c}{ \% Passing } & \% Retained & Weight $(\mathrm{G})$ \\
& Min. & Max. & Mid. & & \\
\hline 12.5 & 100 & 100 & 100 & 0 & 0 \\
9.5 & 72 & 83 & 77.5 & 22.5 & 247.5 \\
4.75 & 25 & 38 & 31.5 & 46 & 506 \\
2.36 & 16 & 24 & 20 & 11.5 & 126.5 \\
0.6 & 12 & 16 & 14 & 6 & 66 \\
0.3 & 12 & 15 & 13.5 & 0.5 & 5.5 \\
0.075 & 8 & 10 & 9 & 4.5 & 49.5 \\
Pan & 0 & 0 & 0 & 9 & 99 \\
& & & & $\mathbf{1 0 0}$ & $\mathbf{1 1 0 0}$ \\
\hline
\end{tabular}

a dry process was conducted. In the dry process, the additive (CRM) is blended with the aggregate before adding the binder to the mixture. The binder contents utilised in this study are $5 \%, 5.5 \%, 6 \%, 6.5 \%$, and $7 \%$ by weight of the total mix. The crumb rubber modifier added into the mixture at different concentrations of $6 \%, 12 \%, 16 \%$, and $20 \%$ binder weight. In current study $5 \%$ filler was used. For preparing SMA mixtures, $1100 \mathrm{~g}$ of mixed aggregate was placed in the oven at $160^{\circ} \mathrm{C}$ for $2 \mathrm{~h}$. Bitumen was also heated at $120^{\circ} \mathrm{C}$ before mixing with aggregate particles. As the method of dry process, crumb rubber modifier was added directly to the mixture. Mixing temperature was kept constant at the temperature between 160 and $165^{\circ} \mathrm{C}$. The mixture was transferred into a Marshall
TABLE 5: Stability results $(\mathrm{kN})$ for different CRM contents.

\begin{tabular}{lccccc}
\hline & \multicolumn{5}{c}{ Binder content } \\
& $5 \%$ & $5.5 \%$ & $6 \%$ & $6.5 \%$ & $7 \%$ \\
\hline CR 0\% & 11.99 & 13.10 & 12.5 & 11.40 & 10.8 \\
CR 6\% & 11.50 & 12.90 & 11.9 & 10.89 & 10.7 \\
CR 12\% & 10.55 & 11.80 & 11.4 & 10.90 & 9.8 \\
CR 16\% & 10.40 & 10.40 & 11.99 & 9.4 & 9.4 \\
CR 20\% & 8.9 & 9.30 & 10.89 & 9.7 & 8.3 \\
\hline
\end{tabular}

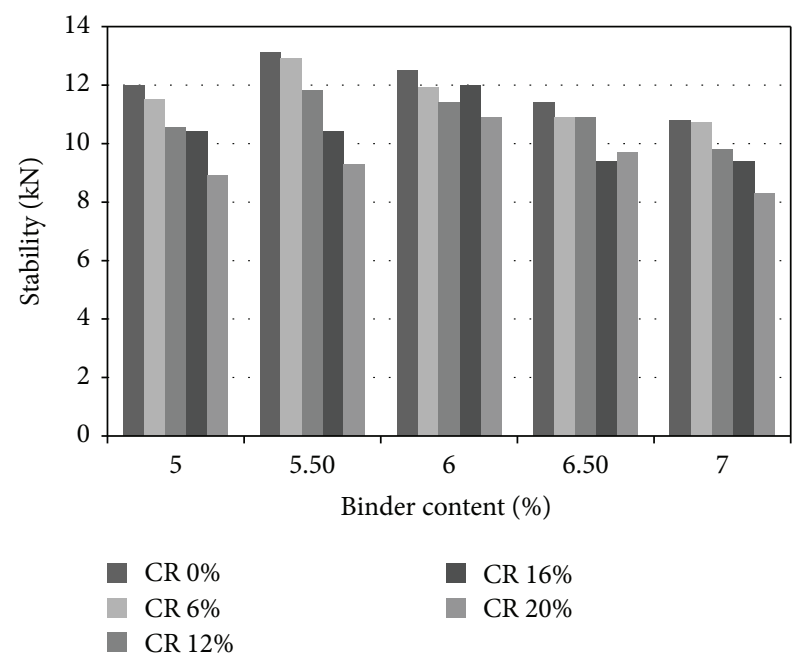

FIGURE 1: Stability results versus binder content.

mould. The stainless steel thermometer was put in the centre of the mould and mixture was then ready for compaction at temperature of $160 \pm 5^{\circ} \mathrm{C}$. All samples were subjected to 50 blows of compaction by Marshall Hammer on each side of specimen at temperature of $145^{\circ} \mathrm{C}$. The laboratory tests used to investigate and evaluate the performance properties of SMA bitumen mixture modified with CRM samples were Standard Test Method for resistance of plastic flow of bituminous materials using Marshall apparatus [21] and Standard Test Method for Indirect Tensile Strength Test of Bituminous Mixtures [22].

\section{Results and Discussion}

\subsection{Marshall Test Results}

3.1.1. Marshall Stability. The results obtained for various CRM contents for each binder content are shown in Table 5 and illustrated in Figures 1 and 2.

The Marshall stability refers to the maximum load resistance escalated during the test procedure at $60^{\circ} \mathrm{C}$ at a loading rate of $50.8 \mathrm{~mm} / \mathrm{min}$, before the compacted specimen failure. The Marshall stability is defined "as a measurement of the susceptibility of a bituminous mixture to deformation ensuring from frequent and heavy traffic load."

Figures 1 and 2 illustrate the Marshall stability value versus CRM content for different binder contents. The diagrams show the stability values for the differing binder content 


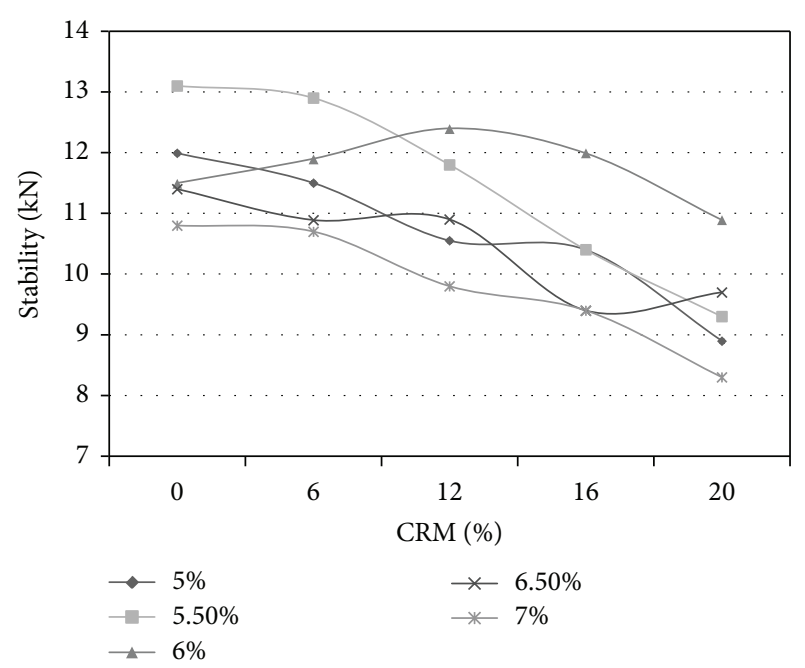

Figure 2: Stability results versus CRM content.

TABLE 6: Flow results (mm) for different CRM contents.

\begin{tabular}{lccccc}
\hline & \multicolumn{5}{c}{ Binder content } \\
& $5 \%$ & $5.5 \%$ & $6 \%$ & $6.5 \%$ & $7 \%$ \\
\hline CR 0\% & 3.0 & 3.2 & 3.5 & 4 & 4.4 \\
CR 6\% & 3.4 & 3.4 & 3.7 & 4.7 & 5.6 \\
CR 12\% & 3.5 & 4.1 & 4.1 & 4.4 & 5.2 \\
CR 16\% & 2.4 & 3.2 & 3 & 3.6 & 4.4 \\
CR 20\% & 2.2 & 2.3 & 2.5 & 2.8 & 3.3 \\
\hline
\end{tabular}

varying in tandem with the CRM content. Once CRM is added the stability value elevated until the maximum level, which was approximately $12 \%$ of the used CRM, but then it started to decrease. In comparison to the control mix (mix with 0\% CRM), the values of Marshall stability were generally higher. Nevertheless, further injection of bitumen into the mixture led to a decrease in the value of stability because application of excessive bitumen decreases the coarse aggregate contact point within the mixture. Only mixture with a lower stability value was the mixture with $20 \%$ CRM. Stability is improved by adding CRM binders to the stone mix asphalt as better adhesion is developed between the materials in the mix $[9,23]$.

3.1.2. Marshall Flow. Flow can be understood to mean a measurement of the permanent strain which takes place in a Marshall test at failure. It had indicated that the flow parameter as obtained from the Marshall test is rather unfortunate as a higher flow value does not necessary imply a higher tendency to flow or deform under load [23]. The results obtained for various CRM contents for each binder content are shown in Table 6 and illustrated in Figures 3 and 4.

Figure 3 illustrates the Marshall flow value versus binder content for each CRM content. The results showed that the flow value increases with an increase in the bitumen content in the mixture; that is, the SMA flow value tends to increase

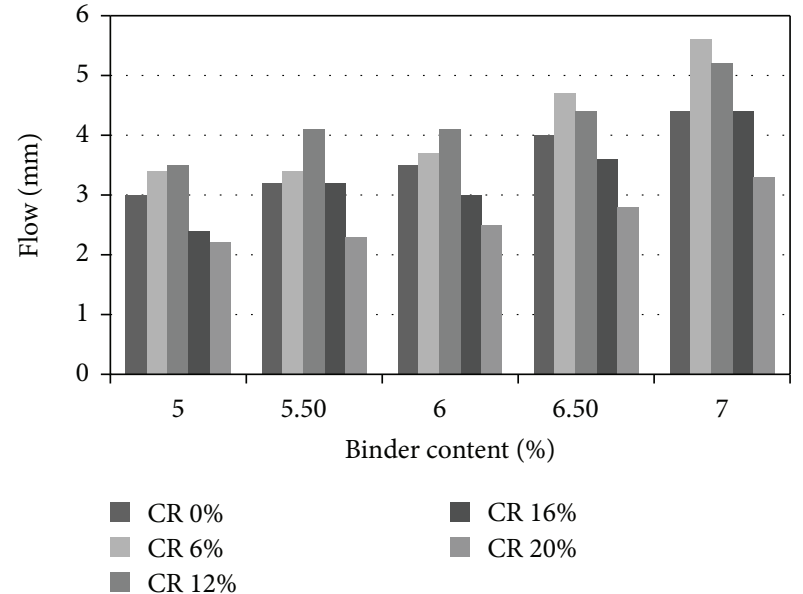

Figure 3: Flow results versus binder content.

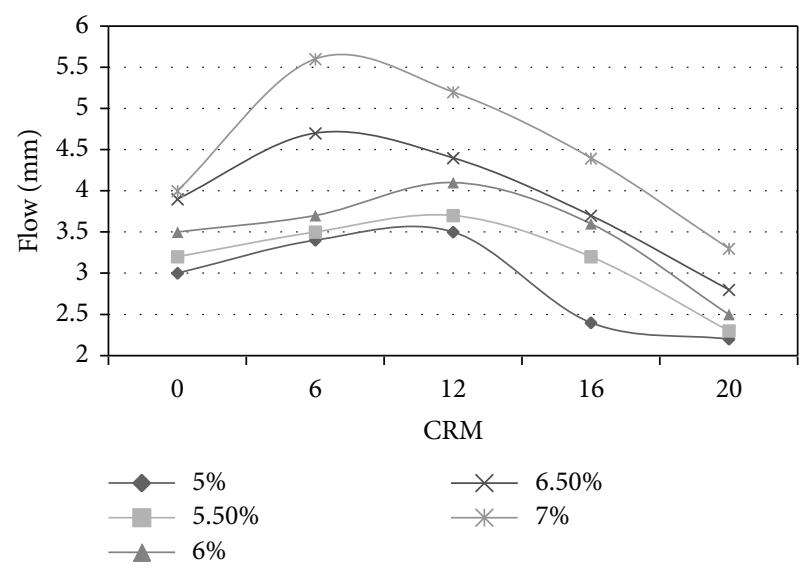

FIGURE 4: Flow results versus CRM content.

with a higher binder content. This is due to the percentage of additional bitumen which allows the aggregates to float within the mix resulting in increased flow.

In the case of the relationship between the Marshall flow and CRM content (Figure 4), the flow value of SMA with CRM is higher in comparison with the SMA without CRM. As shown in Figure 4, the presence of CRM in the mixture increases its flow value. Also, it shows that the increase in CRM content in the SMA mixture does not necessary increase the flow values. The addition of more CRM contents increased the flow to an optimum level and with further addition of CRM in the mix; it was observed that there was an obvious decrease. Higher flow values may be related to the increase of air voids (more compaction required) by using more CRM in the mixture, which leads to a more flexible mixture $[9,23]$.

3.1.3. Density of the Compacted Mix (CDM). The results obtained indicated that binder content influences the compaction characteristics of the SMA mixtures, thus having a significant effect on the mix density. Table 7 and Figures 5 and 6 showed that, for any specific binder content, the density of 


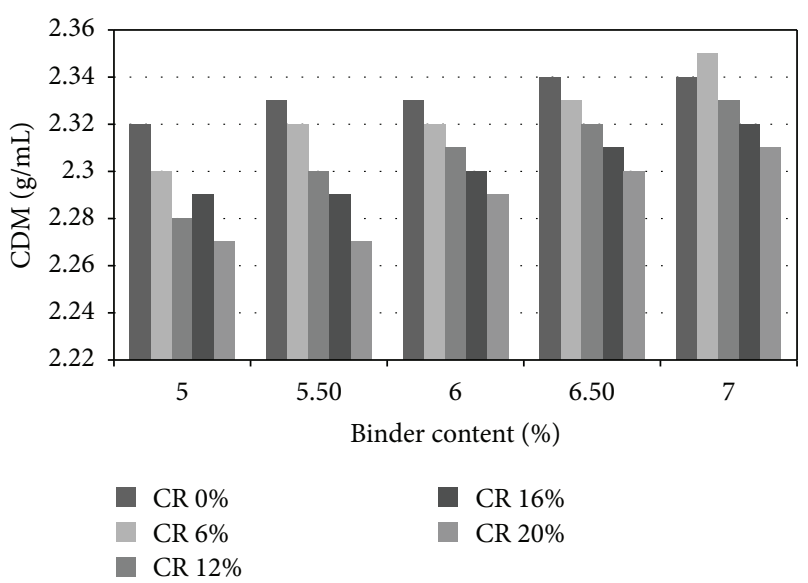

FIGURE 5: CDM results versus binder content.

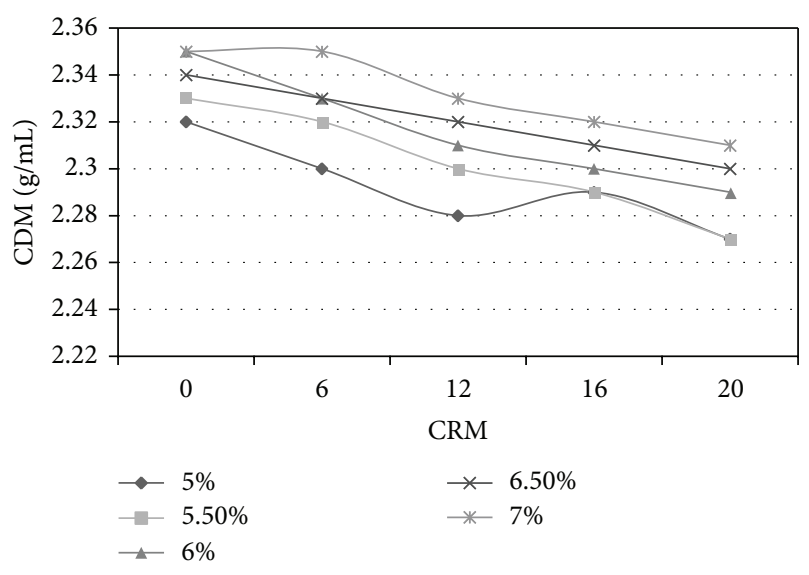

Figure 6: CDM results versus CRM content.

TABLE 7: CDM results $(\mathrm{g} / \mathrm{mL})$ for different CRM contents.

\begin{tabular}{lccccc}
\hline & \multicolumn{5}{c}{ Binder content } \\
& $5 \%$ & $5.5 \%$ & $6 \%$ & $6.5 \%$ & $7 \%$ \\
\hline CR 0\% & 2.32 & 2.33 & 2.35 & 2.34 & 2.35 \\
CR 6\% & 2.30 & 2.32 & 2.33 & 2.33 & 2.35 \\
CR 12\% & 2.28 & 2.30 & 2.31 & 2.32 & 2.33 \\
CR 16\% & 2.29 & 2.29 & 2.30 & 2.31 & 2.32 \\
CR 20\% & 2.27 & 2.27 & 2.29 & 2.30 & 2.31 \\
\hline
\end{tabular}

the compacted mix is progressively increased, as the bitumen content of the mix increases. This is due to the bitumen filling in the void space of the aggregate particles.

The results indicated a lower density for the mixtures with incorporation of crumb rubber. Assessing the results concerning the effect of bitumen content in CDM (Figure 5) showed that the CDM value increases with increasing bitumen content in the SMA mixture. The main reason for this is because of filling of the void space of the aggregate particles with bitumen. However, after filling the void space, the excessive percentage of the bitumen could lead to a significant increase in the density of the mixture.
TABLE 8: VIM results (\%) for different CRM content.

\begin{tabular}{lccccc}
\hline & \multicolumn{5}{c}{ Binder content } \\
& $5 \%$ & $5.5 \%$ & $6 \%$ & $6.5 \%$ & $7 \%$ \\
\hline CR 0\% & 6.24 & 5.38 & 4.19 & 3.36 & 2.25 \\
CR 6\% & 7.34 & 6.37 & 4.78 & 4.19 & 3.45 \\
CR 12\% & 7.56 & 6.65 & 5.28 & 4.45 & 3.56 \\
CR 16\% & 7.57 & 6.98 & 5.43 & 4.89 & 3.68 \\
CR 20\% & 7.83 & 7.40 & 5.81 & 5.10 & 3.96 \\
\hline
\end{tabular}

Figure 6 showed that, for any binder content, the density decreased as the crumb rubber is increased in the SMA mixtures. The increase in CRM content implies an increase of the bitumen absorbed by the CRM causing more voids space with the aggregate particles therefore a reduction in mix density. An explanation for the varying densities of the mixtures is because of the viscosity effect on the compatibility of the mixtures. The increase in viscosity could be a result of the amount of asphaltenes in the bitumen which improves the viscous flow of the modified bitumen sample during the interaction process. The higher viscosity of the resulting binder provided better resistance during compaction of the mixture, thus resulting in lower density of the modified mix. This is in concurrence with previous finding by Mahrez [23], which revealed that for ideal paving mixture a good correlation between binder viscosity and the compaction effort is required.

3.1.4. Voids in the Mix (VIM). The durability of bituminous pavement is a function of the voids of the mix (VIM) or porosity. In general, the lower the porosity, the less permeable the mixture and vice versa. Too much voids in the mix (high porosity) will provide passageways through the mix for the entrance of damaging air and water. Too low porosity could lead to flushing where the excess bitumen squeezes out of the mix to the surface. The effect of the CRM content for different binder contents on the porosity of the virgin mixture and SMA mixture shown in Table 8 and Figures 7 and 8.

Figures 7 and 8 show that, for any binder content used, the increase in CRM content in the mixture is followed by an increase in the VIM, which is due to the contact point between the aggregates which is lower when the CRM is content increased. The high amount of crumb rubber particle absorbs the binder which is required to encapsulate the aggregate and subsequently fill the voids between aggregates. High porosity in the bituminous mixture means that there are many voids providing passageways for the entry of damaging air and water through the mix. On the other hand, with low porosity, water flush occurs whereby bitumen is squeezed out of the mix to the surface [23]. However, the results from Figure 7 concerning on the influence of bitumen show that any increase in the bitumen content of the mix leads to a decrease in the VIM value, which occurs due to the excessive bitumen filling up the air pocket between aggregates [24]. It is therefore very important to produce a mix low enough in void to be impermeable and hence durable, but with sufficient voids to prevent bitumen deformation. 


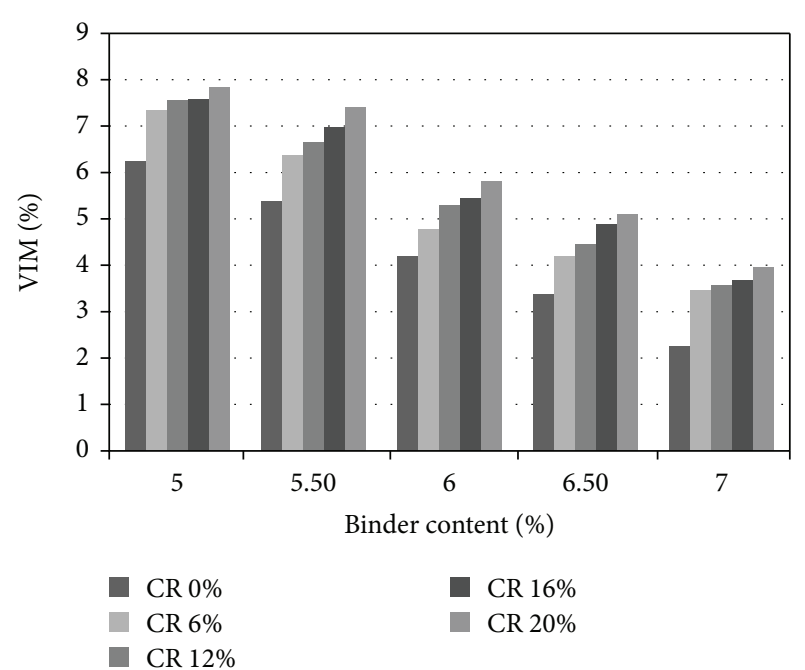

FIGURE 7: VIM results versus binder content.

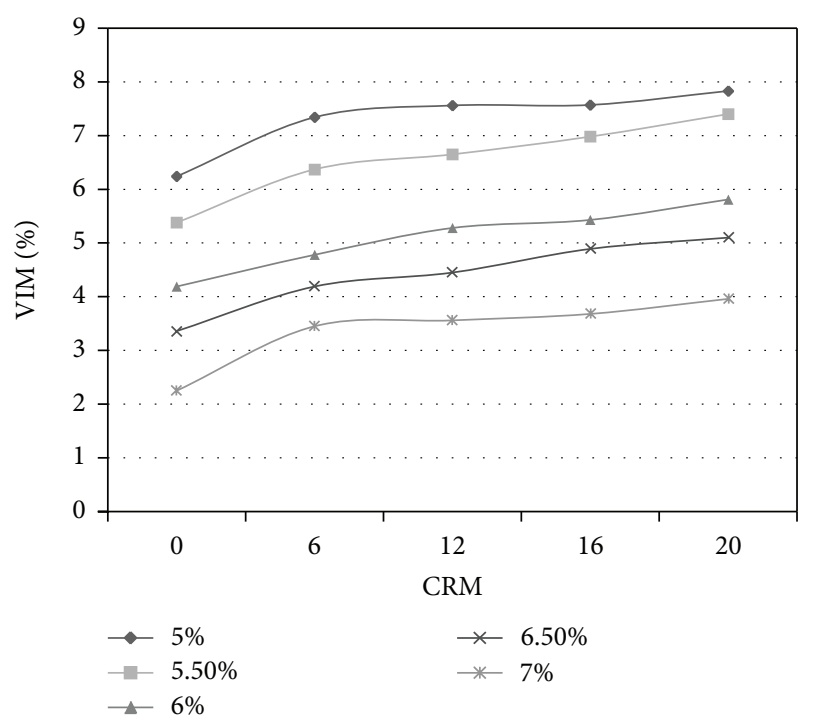

FIGURE 8: VIM results versus CRM content.

3.2. Indirect Tensile Test Results (Stiffness Modulus). In order to determine the stiffness modulus, the resilient modulus of specimens was conducted in accordance with [22] at $25^{\circ} \mathrm{C}$. In asphalt samples, as a result of the excess strain, cracks appeared in relation to the tensile strength which was primarily microcracks. These cracks were perpendicular to the maximum tensile stress direction; integrating these microcracks by increasing the deformation results in a generation of macrocracks. In tandem with the investigations, these cracks led to a fracture zone in the specimen. The length of this fracture zone can be viewed as a material parameter and can be construed to be a result of the fractureenergy of the material. Temperature and bitumen percentage are the two principal parameters which significantly influence the asphalt characteristics.

Table 9 and Figures 9 and 10 show the stiffness modulus $(\mathrm{Mr})$ variation against bitumen content for asphalt mixtures

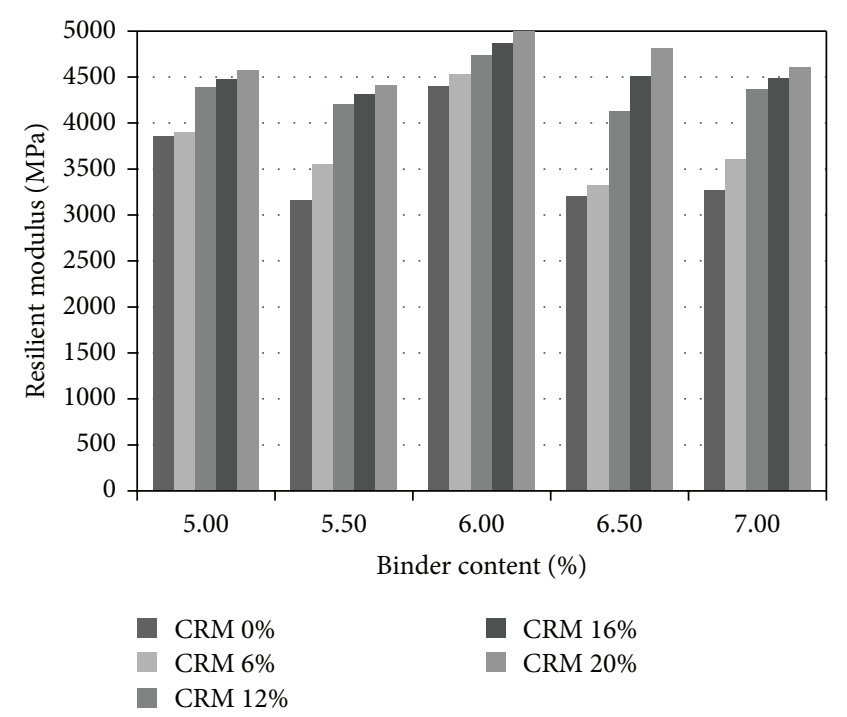

FIgURE 9: Resilient modulus versus Bitumen content.

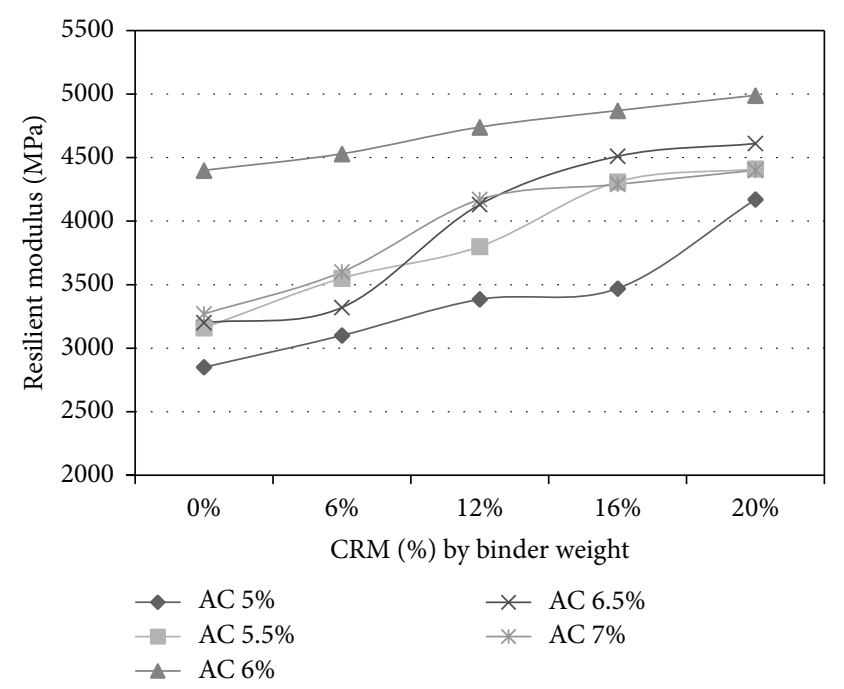

FIgURE 10: Resilient modulus versus CRM content.

TABLE 9: Stiffness modulus results (Mpa) for different CRM contents.

\begin{tabular}{lccccc}
\hline & \multicolumn{5}{c}{ Binder content } \\
& $5 \%$ & $5.5 \%$ & $6 \%$ & $6.5 \%$ & $7 \%$ \\
\hline CR 0\% & 3850 & 3160 & 4400 & 3200 & 3270 \\
CR 6\% & 3900 & 3550 & 4530 & 3320 & 3600 \\
CR 12\% & 4384 & 4200 & 4740 & 4130 & 4370 \\
CR 16\% & 4470 & 4310 & 4870 & 4510 & 4489 \\
CR 20\% & 4570 & 4410 & 4990 & 4810 & 4600 \\
\hline
\end{tabular}

reinforced with different contents of CRM and nonreinforced asphalt mixture (containing 0\% CRM). As revealed in Figures 9 and 10, there is a marked variation between the reinforced and nonreinforced samples in the stiffness modulus (Mr). The increased bitumen has a significant impact on the stiffness modulus of specimens with varying CRM contents, due 
to the effect of the optimum bitumen percent being lower in nonreinforced samples. In reinforced asphalt samples with CRM, the crumb rubber content absorbs a portion of bitumen resulting in the optimum binder percent to increase. As the crumb rubber content is increased, more bitumen is absorbed, which in turn increases the optimum binder content of the mix. It is evident that the stiffness modulus of reinforced asphalt samples is higher compared to the nonreinforced samples.

Mixes with higher stiffness suggest that, apart from being stiffer, they are more resistant to deformation. However, care must be exercised with very high stiffness mixes due to their lower tensile strain capacity to failure; that is, such mixes are more likely to fail by cracking particularly when laid over foundations which fail to provide adequate support [23].

\section{Conclusion and Recommendation for Future Studies}

Based on the study conducted, the following conclusions may be derived.

(1) Stability is improved by adding CRM binders to the stone mix asphalt as better adhesion is developed. In comparison to the control mix (mix with $0 \% \mathrm{CRM}$ ), the values of Marshall stability were generally higher.

(2) Regardless of the amount of the incorporated CRM, adding CRM to the mixture increases the VIM of the mixture while decreasing its density.

(3) The stiffness modulus of SMA samples containing various contents of CRM is significantly higher in comparison with that of nonreinforced samples.

(4) The appropriate amount of the added CRM was found to be $12 \%$ by weight of bitumen. This percentage results in the maximum level of stability and VIM.

(5) The volumetric and Marshall properties of CRMSMA mixture show acceptable trends and could satisfy the standard requirements.

(6) Use of different types of aggregate, aggregate gradation, different mixing methods, and different compaction methods is recommended for further studies.

\section{References}

[1] S. J. Rozeveld, E. Shin, A. Bhurke, L. France, and L. Drzal, "Network morphology of straight and polymer modified asphalt cements," Microscopy Research and Technique, vol. 38, no. 5, pp. 529-543, 1997.

[2] R. Richard and T. Bent, Road Engineering for Development, Spon Press, London, UK, 2nd edition, 2004.

[3] E. R. Brown and M. Hemant, "Evaluation of Labrotary properties of SMA mixture," NCATR Report No. 93-5, National Center for Asphalt Technology, Auburn University, 1993.

[4] N. S. Mashaan, The effect of crumb rubber modifier to the properties and rheological behaviour of asphalt binder [M.S. thesis], University of Malaya, Kuala Lumpur, Malaysia, 2012.
[5] Y. Huang, R. N. Bird, and O. Heidrich, "A review of the use of recycled solid waste materials in asphalt pavements," Resources, Conservation and Recycling, vol. 52, no. 1, pp. 58-73, 2007.

[6] D. C. Thompson and A. J. Hoiberg, Eds., Bituminous Materials: Asphalt Tars and Pitches, Krieger Publishing, New York, NY, USA, 1979.

[7] U. Isacsson and X. Lu, "Characterization of bitumens modified with SEBS, EVA and EBA polymers," Journal of Materials Science, vol. 34, no. 15, pp. 3737-3745, 1999.

[8] Y. Yildirim, "Polymer modified asphalt binders," Construction and Building Materials, vol. 21, no. 1, pp. 66-72, 2007.

[9] A. Mahrez, Properties of rubberised bitumen binder and its effect on the bituminous mix [M.S. thesis], Faculty of Engineering, University of Malaya, Kuala Lumpur, Malaysia, 1999.

[10] L. Raad and S. Saboundjian, "Fatigue behavior of rubbermodified pavements," Transportation Research Record, no. 1639, pp. 73-82, 1998.

[11] J. R. Lundy, R. G. Hicks, and H. Zhou, "Ground rubber tires in asphalt-concrete mixtures-three case histories," ASTM Special Technical Publication, STP1193, pp. 262-275, 1993.

[12] H. Zhu and D. D. Carlson, "A spray based crumb rubber technology in highway noise reduction application," Journal of Solid Waste Technology and Management, vol. 27, no. 1, pp. 2733, 2001.

[13] Z. Sufian and M. S. Mustafa, "Prospects of rubberised bitumen pavement Malaysia roads and highways," in Proceedings of the Conference on the Use of Rubberised Bitumen in the Road Construction, 1997.

[14] A. Samsuri, S. Hasshim, M. H. Harun, and A. L. M. Dewa, "Rubberised-bitumen for road construction," in Proceedings of the International Conference on the Usage of Rubber in Engineering Technology, Kuala Lumpur, Malaysia, 1995.

[15] N. S. Mashaan, A. H. Ali, M. R. Karim, and M. Abdelaziz, "Effect of crumb rubber concentration on the physical and rheological properties of rubberised bitumen binders," International Journal of Physical Sciences, vol. 6, no. 4, pp. 684-690, 2011.

[16] N. S. Mashaan, A. H. Ali, M. R. Karim, and M. Abdelaziz, "Effect of blending time and crumb rubber content on properties of crumb rubber modified asphalt binder," International Journal of Physical Sciences, vol. 6, no. 9, pp. 2189-2193, 2011.

[17] N. S. Mashaan, A. H. Ali, M. R. Karim, and M. Abdelaziz, "An overview of crumb rubber modified asphalt," International Journal of Physical Sciences, vol. 7, no. 2, pp. 166-170, 2012.

[18] N. S. Mashaan and M. R. Karim, "Investigating the rheological properties of crumb rubber modified bitumen and its correlation with temperature susceptibility," Materials Research, vol. 16, no. 1, pp. 116-127, 2013.

[19] A. H. Ali, N. S. Mashaan, and M. R. Karim, "Investigations of physical and rheological properties of aged rubberised bitumen," Advances in Materials Science and Engineering, vol. 2013, Article ID 239036, 7 pages, 2013.

[20] Jabatan Kerja Raya Malaysia (JKR), Standard Specification for Road Work, Jabatan Kerja Raya Malaysia, Kuala Lumpur, Malaysia, 2007.

[21] ASTM D1559-89, "Standard test method for resistance to plastic flow of bituminous mixtures using Marshall Apparatus," 1992.

[22] ASTM D, 4123-82, "Standard test method for indirect tension test for resilient modulus of bituminous mixtures," 1995.

[23] A. Mahrez, Properties and performance of stone mastic asphalt reinforced with glass fibre [Ph.D. thesis], Faculty of Engineering, University of Malaya, Kuala Lumpur, Malaysia, 2008. 
[24] I. M. Asi, "Laboratory comparison study for the use of stone matrix asphalt in hot weather climates," Construction and Building Materials, vol. 20, no. 10, pp. 982-989, 2006. 

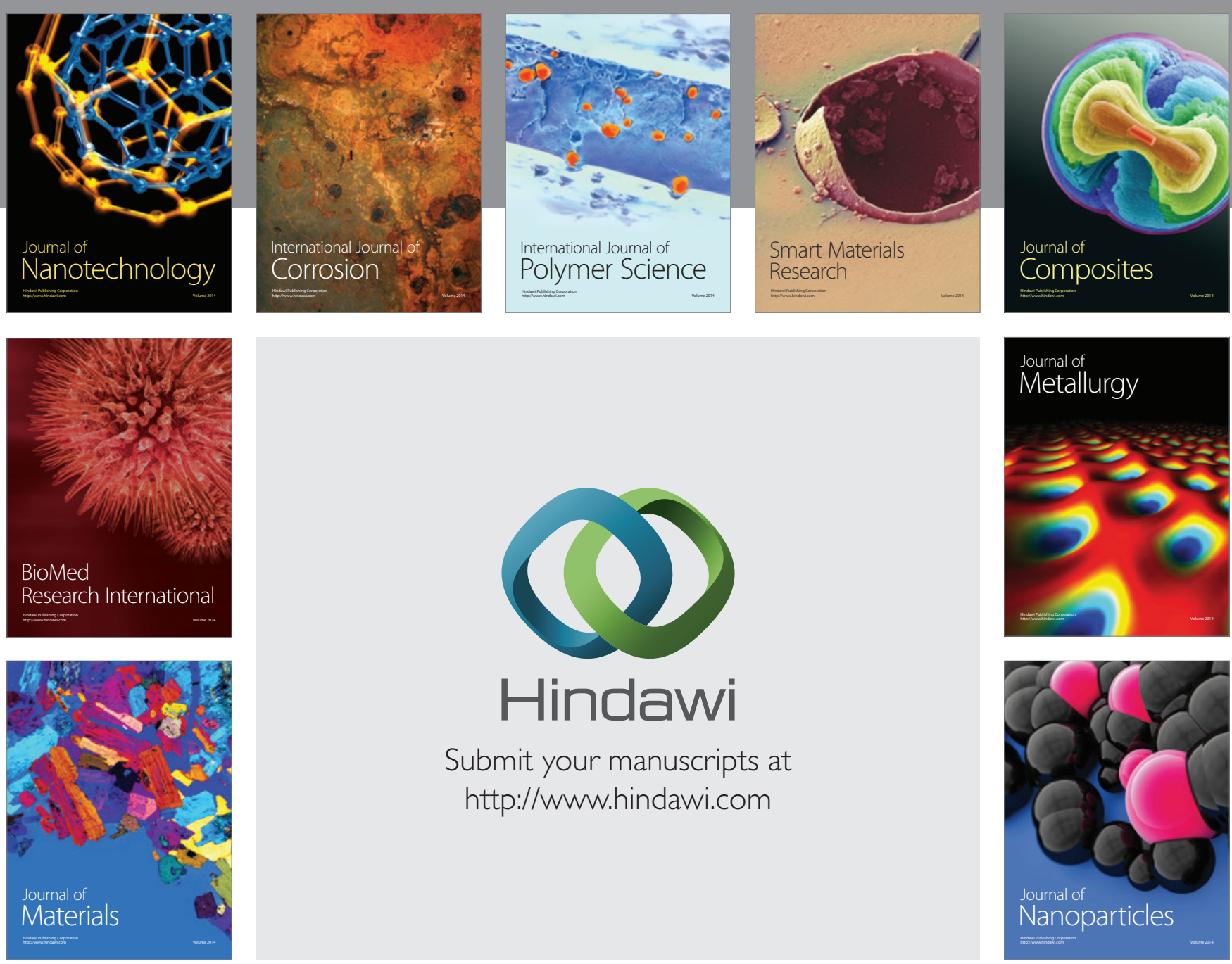

Submit your manuscripts at http://www.hindawi.com
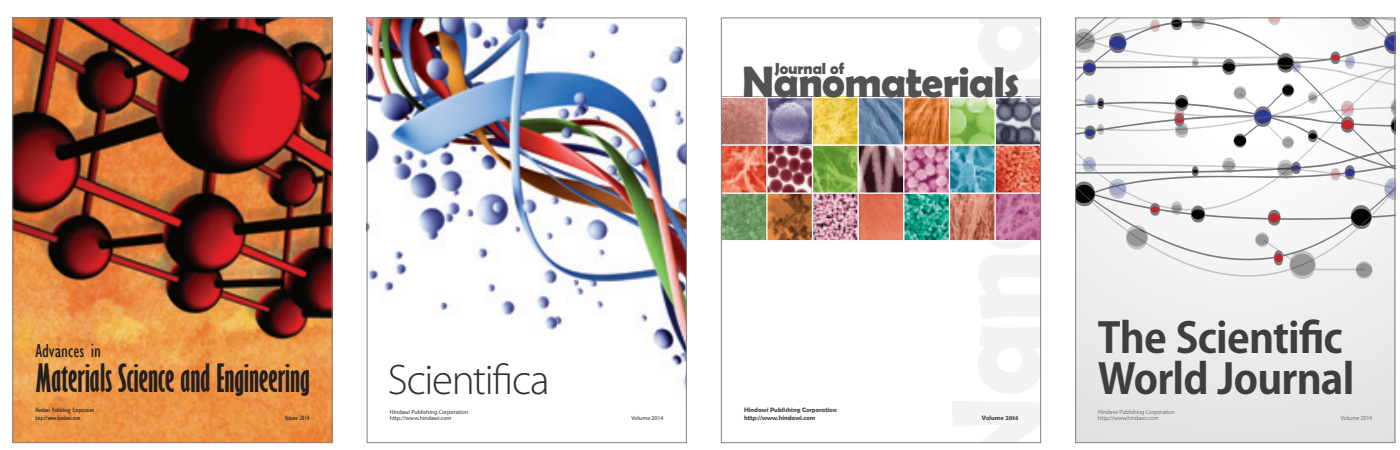

\section{The Scientific World Journal}
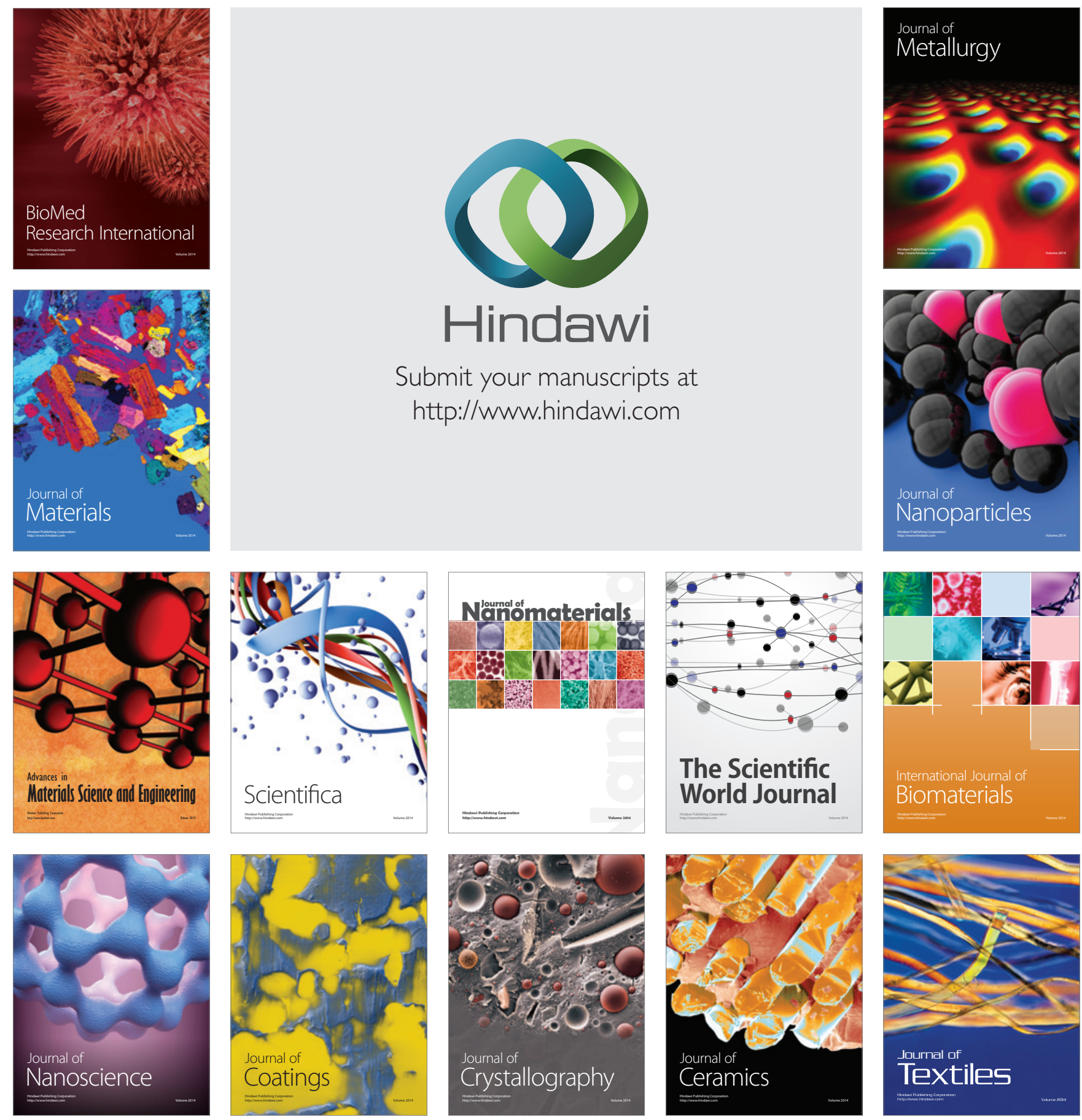